\title{
Magnetic Properties and Phase Constitution of the Nanocrystalline $\left(\mathrm{Nd}_{10} \mathrm{Fe}_{67} \mathrm{~B}_{23}\right)_{100-x} \mathrm{Nb}_{x}$ (where $x=1,2,3,4$ ) Alloy Ribbons
}

\author{
M. Kaźmierczak, K. Pawlik, P. Pawlik, P. Gębara, A. PrzybyŁ, J.J. WysŁocki \\ Institute of Physics, Częstochowa University of Technology, Armii Krajowej 19, 42-200 Częstochowa, Poland
}

(Received February 2, 2015)

In the present work the magnetic properties and phase constitution of $\left(\mathrm{Nd}_{10} \mathrm{Fe}_{67} \mathrm{~B}_{23}\right)_{100-x} \mathrm{Nb}_{x}$ (where $x=1$, $2,3,4)$ alloys in a form of ribbons were investigated. The ribbon samples were obtained by controlled atmosphere melt-spinning technique. In order to generate the nanocrystalline microstructure, ribbons were annealed at various temperatures (from $923 \mathrm{~K}$ to $1023 \mathrm{~K}$ ) for $5 \mathrm{~min}$. Subsequent annealing resulted in an evolution of the phase constitution accompanied by a change of their magnetic properties. The X-ray diffraction studies show presence of hard magnetic $\mathrm{Nd}_{2} \mathrm{Fe}_{14} \mathrm{~B}$, paramagnetic $\mathrm{Nd}_{1+\varepsilon} \mathrm{Fe}_{4} B_{4}$ and ferromagnetic metastable $\mathrm{Nd}_{2} \mathrm{Fe}_{23} \mathrm{~B}_{3}$ phases. The best hard magnetic parameters were measure for annealed ribbons of the $\left(\mathrm{Nd}_{10} \mathrm{Fe}_{67} \mathrm{~B}_{23}\right)_{96} \mathrm{Nb}_{4}$ alloy.

DOI: 10.12693/APhysPolA.128.91

PACS: 75.20.En, 91.60.Pn

\section{Introduction}

In modern technology permanent magnets are used as key components of electromechanical, electronic and medical devices [1, 2]. Nanocrystalline RE-Fe-B-based magnets have attracted much attention since their discovery in 1984 [3, 4] and have been extensively studied until now. Much of the work was focused on $\mathrm{Nd}-$ $\mathrm{Fe}-\mathrm{B}$ and $\mathrm{Pr}-\mathrm{Fe}-\mathrm{B}$ alloys [5-9], due to their excellent hard magnetic properties. The microstructure and phase constitution have significant influence on coercivity ${ }_{J} H_{\mathrm{c}}$, remanence $B_{\mathrm{r}}$ and maximum energy product $(B H)_{\max }$. In recent years, one of the most frequently used methods for production of magnets is the melt-spinning technique. In order to obtain optimal magnetic properties, appropriate alloy composition as well as suitable heat treatment, are crucial issues [5].

Currently, the bulk rapidly solidified nanocrystalline of $\mathrm{Nd}-\mathrm{Fe}-\mathrm{B}$ and $\mathrm{Pr}-\mathrm{Fe}-\mathrm{B}$ alloys doped with $\mathrm{Nb}$, with a high boron content, produced in a form of amorphous rods, tubes or plates, are intensively studied [6]. Relatively high coercivities were measured for $1 \mathrm{~mm}$ diameter rod samples of $\mathrm{Nd}-\mathrm{Fe}-\mathrm{B}$ alloy doped with 4 at.\% of $\mathrm{Nb}[7,8]$. Furthermore, it was shown in [9] that large content of $B$ influences glass forming abilities (GFA), of this group of alloys, while $\mathrm{Nb}$ addition has a significant impact not only on the GFA, but also retards the growth of nanocrystalline grains formed during annealing $[9,10]$. The heat treatment process is an important factor leading to optimization of magnetic properties of magnets. The aim of the present work was to determine the influence of $\mathrm{Nb}$ addition and annealing conditions on the phase constitution and magnetic properties of ribbons produced from the $\left(\mathrm{Nd}_{10} \mathrm{Fe}_{67} \mathrm{~B}_{23}\right)_{100-x} \mathrm{Nb}_{x}$ (where $\left.x=1,2,3,4\right)$ alloys.

\section{Experimental material and methods}

The ingot samples of nominal composition of $\left(\mathrm{Nd}_{10} \mathrm{Fe}_{67} \mathrm{~B}_{23}\right)_{100-x} \mathrm{Nb}_{x}$ (where $\left.x=1,2,3,4\right)$ were prepared by arc-melting under an argon atmosphere the high purity constituent elements with addition of prealloyed $\mathrm{Fe}-\mathrm{B}$ of known composition. The samples were remelted several times in order to obtain homogeneity. Next, ribbon samples were prepared by melt-spinning technique under the Ar atmosphere. In order to generate amorphous structure the linear speed of the copper roll surface of $35 \mathrm{~m} / \mathrm{s}$ was used. Subsequently the ribbon samples were sealed/Of in a quartz tubes under low pressure of argon to maintain the purity of atmosphere during heat treatment. In order to obtain a nanocrystalline microstructure, the samples were heat treated at temperatures ranging from $923 \mathrm{~K}$ to $1023 \mathrm{~K}$ for $5 \mathrm{~min}$. The phase analysis of these samples was studied using X-ray diffractometry (XRD) with $\mathrm{Cu} K_{\alpha}$ radiation. Hysteresis loops were measured by LakeShore 7307 vibrating sample magnetometer at external magnetic field up to $2 \mathrm{~T}$ at room temperature.

\section{Results}

The XRD scans measured for $\left(\mathrm{Nd}_{10} \mathrm{Fe}_{67} \mathrm{~B}_{23}\right)_{100-x} \mathrm{Nb}_{x}$ (where $x=1,2,3,4$ ) alloy ribbons in as-cast state are shown in Fig. 1. This studies suggest presence of amorphous structure, evidenced by the lack of peaks corresponding to crystalline phases for all alloy compositions. Annealing at $923 \mathrm{~K}$ and $943 \mathrm{~K}$ for 5 min resulted in small changes in the crystal structure of the material (Figs. 2, 3). Broadened peaks originating from crystalline phase are observed on the diffraction patterns. The low intensity of these peaks in comparison to the background did not allow to clearly identify crystalline phases present in the sample.

The XRD patterns measured for the compound $\left(\mathrm{Nd}_{10} \mathrm{Fe}_{67} \mathrm{~B}_{23}\right)_{100-x} \mathrm{Nb}_{x}$ (where $\left.x=1,2,3,4\right)$ alloy ribbon samples annealed at $963 \mathrm{~K}$ for $5 \mathrm{~min}$, are shown in Fig. 4.

Annealing for $5 \mathrm{~min}$ at $963 \mathrm{~K}$ and higher temperatures, led to nucleation and growth of the crystalline phases. 


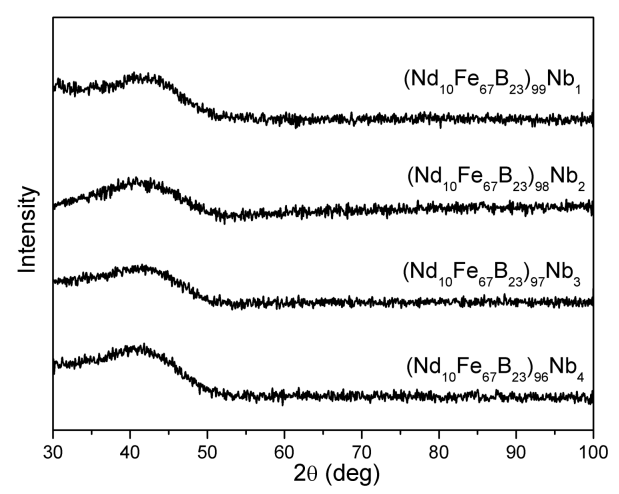

Fig. 1. X-ray diffraction patterns of as-cast $\left(\mathrm{Nd}_{10} \mathrm{Fe}_{67} \mathrm{~B}_{23}\right)_{100-x} \mathrm{Nb}_{x}$ (where $\left.x=1,2,3,4\right)$ alloy ribbon samples.

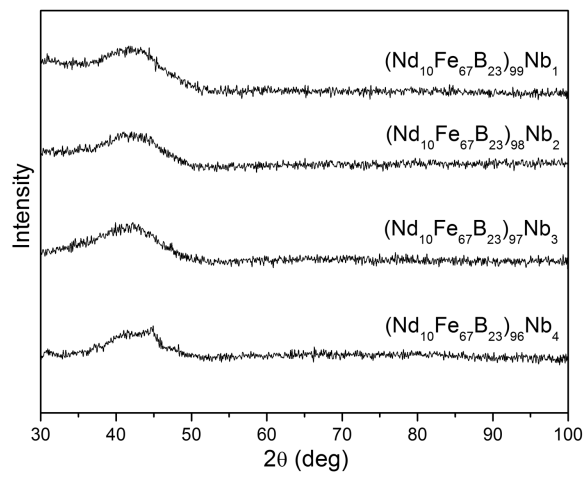

Fig. 2. X-ray diffraction patterns of the compound $\left(\mathrm{Nd}_{10} \mathrm{Fe}_{67} \mathrm{~B}_{23}\right)_{100-x} \mathrm{Nb}_{x}$ (where $\left.x=1,2,3,4\right)$ alloy ribbon samples annealed at $923 \mathrm{~K}$ for $5 \mathrm{~min}$.

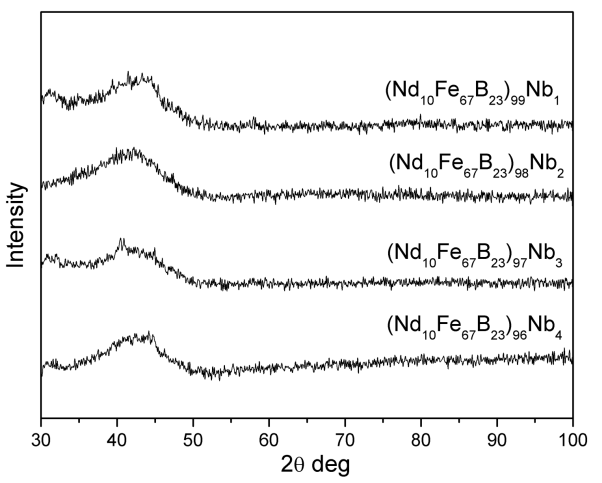

Fig. 3. As in Fig. 2, but for $943 \mathrm{~K}$.

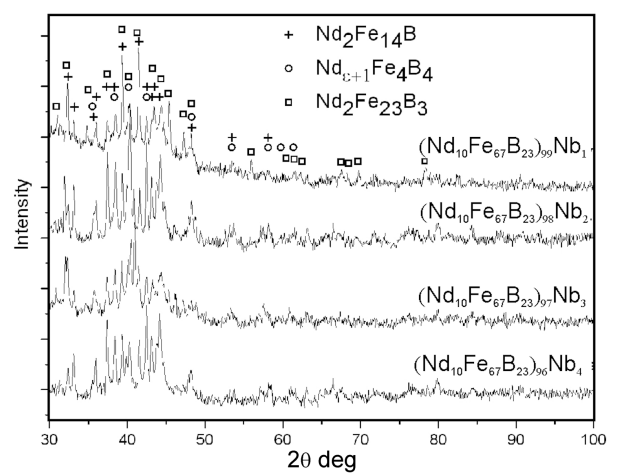

Fig. 4. As in Fig. 2, but for $963 \mathrm{~K}$.
The main crystalline phase precipitating during annealing was the hard magnetic $\mathrm{Nd}_{2} \mathrm{Fe}_{14} \mathrm{~B}$. The analysis of XRD patterns also indicated a presence of the paramagnetic $\mathrm{Nd}_{\varepsilon+1} \mathrm{Fe}_{4} \mathrm{~B}_{4}$ and metastable $\mathrm{Nd}_{2} \mathrm{Fe}_{23} \mathrm{~B}_{3}$ metastable phases [11]. However, due to the proximity of peaks coming from the $\mathrm{Nd}_{2} \mathrm{Fe}_{14} \mathrm{~B}$, the presence of this phase was confirmed by the Mössbauer spectroscopy. For samples annealed at $963 \mathrm{~K}$ and higher, no change in phase composition of the alloy was observed. Also the intensities of peaks corresponding to the crystalline phases are not significantly changed. However, in case of the $\left(\mathrm{Nd}_{10} \mathrm{Fe}_{67} \mathrm{~B}_{23}\right)_{96} \mathrm{Nb}_{4}$ ribbon annealed at $1023 \mathrm{~K}$ for $5 \mathrm{~min}$ an evolution in the phase composition occurred. Except the dominant $\mathrm{Nd}_{2} \mathrm{Fe}_{14} \mathrm{~B}$ hard magnetic phase, diffraction peaks from soft magnetic $\alpha$-Fe were also observed.

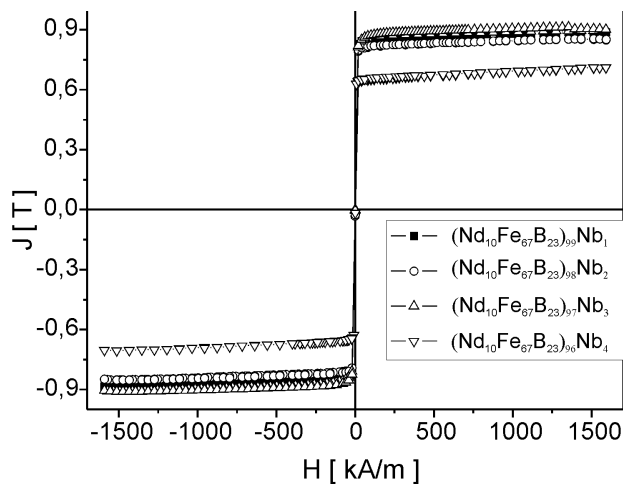

Fig. 5. The hysteresis loops measured for the as-cast $\left(\mathrm{Nd}_{10} \mathrm{Fe}_{67} \mathrm{~B}_{23}\right)_{100-x} \mathrm{Nb}_{x}$ (where $\left.x=1,2,3,4\right)$ alloy ribbon samples.

The hysteresis loops measured for as-cast ribbons are shown in Fig. 5. As-cast ribbons were soft magnetic confirming their fully amorphous structure. Increase of $\mathrm{Nb}$ in the alloy composition resulted in significant decrease of saturation polarization. Annealing at $923 \mathrm{~K}$ and $943 \mathrm{~K}$ resulted in a small change in the shape of hysteresis loops, due to the law fraction of crystalline phases in the constitution of the samples.

The hysteresis loops for ribbons subjected to annealing at $963 \mathrm{~K}$ and $1023 \mathrm{~K}$ for $5 \mathrm{~min}$, are shown respectively in

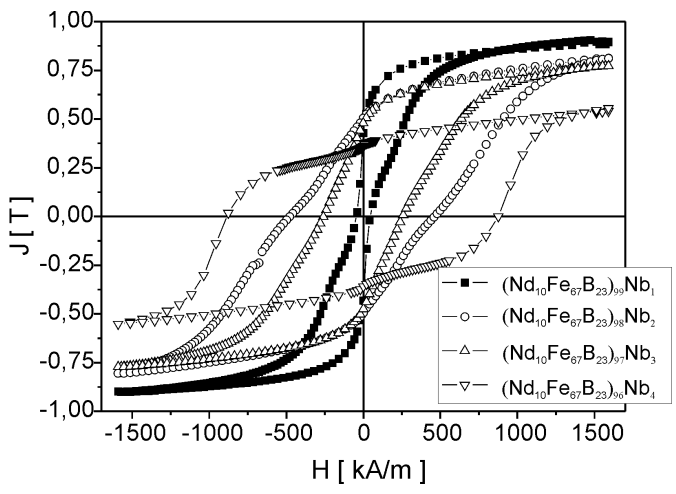

Fig. 6. The hysteresis loops measured for $\left(\mathrm{Nd}_{10} \mathrm{Fe}_{67} \mathrm{~B}_{23}\right)_{100-x} \mathrm{Nb}_{x}$ (where $x=1,2,3,4$ ) alloy ribbon samples annealed at $963 \mathrm{~K}$ for $5 \mathrm{~min}$. 


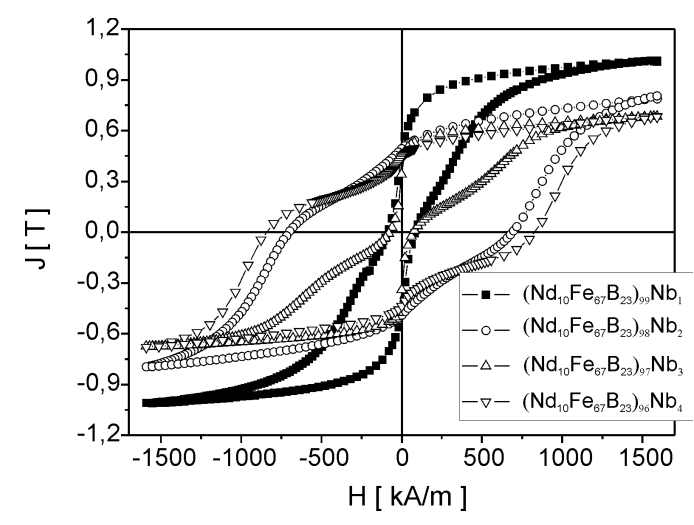

Fig. 7. As in Fig. 6, but for $1023 \mathrm{~K}$.

Figs. 6 and 7. The magnitude of saturation magnetization decreased slightly in comparison to the corresponding as-cast $\left(\mathrm{Nd}_{10} \mathrm{Fe}_{67} \mathrm{~B}_{23}\right)_{100-x} \mathrm{Nb}_{x}$ (where $\left.x=1,2,3,4\right)$ ribbons. The addition of $\mathrm{Nb}$ led to an enhancement of the coercivity.

Further annealing at $1023 \mathrm{~K}$ of ribbons of all compositions resulted in decrease of their magnetic parameters. Especially in case of ribbon containing 4 at.\% of $\mathrm{Nb}$, even though the coercivity reaches $833 \mathrm{kA} / \mathrm{m},(B H)_{\max }$ decreases to $96 \mathrm{~kJ} / \mathrm{m}^{3}$ due to low value of remanence $J_{\mathrm{r}}=0.44 \mathrm{~T}$. Similar results were obtained by Zhang et al. [9] and Tamura et al. [7].

\section{Conclusions}

The magnetic properties and phase constitution of the $\left(\mathrm{Nd}_{10} \mathrm{Fe}_{67} \mathrm{~B}_{23}\right)_{100-x} \mathrm{Nb}_{x}$ (where $\left.x=1,2,3,4\right)$ alloy ribbons annealed at various temperatures from $923 \mathrm{~K}$ to $1023 \mathrm{~K}$ for 5 min were investigated. It was found that $\left(\mathrm{Nd}_{10} \mathrm{Fe}_{67} \mathrm{~B}_{23}\right)_{100-x} \mathrm{Nb}_{x}$ (where $\left.x=1,2,3,4\right)$ alloy ribbons, produced by free jet melt-spinning technique had fully amorphous structure and soft magnetic properties. Heat treatment led to nucleation and growth of the $\mathrm{Nd}_{2} \mathrm{Fe}_{14} \mathrm{~B}$ hard magnetic phase and $\mathrm{Nd}_{\varepsilon+1} \mathrm{Fe}_{4} \mathrm{~B}_{4}$ paramagnetic and $\mathrm{Nd}_{2} \mathrm{Fe}_{23} \mathrm{~B}_{3}$ metastable phases which was confirmed by the Mössbauer spectroscopy. Furthermore, in XRD carried out on the $\mathrm{Nd}_{9.6} \mathrm{Fe}_{64.32} \mathrm{Nb}_{4} \mathrm{~B}_{22.08}$ alloy ribbon annealed at $1023 \mathrm{~K}$, confirmed presence of the soft magnetic $\alpha$-Fe phase. Magnetic studies have revealed that the heat treatment led to nanocrystalline structure of ribbon samples and good magnetic properties. Furthermore, it was found that the relevant contents of niobium has a significant influence on the magnetic properties. The ribbon samples containing 4 at.\% of Nb exhibit the best magnetic properties.

\section{References}

[1] M.T. Thompson, Proc. IEEE 97, 1 (2009).

[2] J.I. Betancourt, Rev. Mexic. Fis. 48, 283 (2002).

[3] J.J. Croat, J.F. Herbst, R.W. Lee, F.E. Pinkerton, J. Appl. Phys. 55, 2078 (1984).

[4] M. Sagawa, S. Fujimura, N. Togawa, H. Yamamoto, J. Matsuura, J. Appl. Phys. 55, 2083 (1984).

[5] A. Manaf, R.A. Buckley, H.A. Davies, J. Magn. Magn. Mater. 128, 302 (1993).

[6] K. Pawlik, P. Pawlik, J.J. Wysłocki, Acta Phys. Pol. A 118, 900 (2010).

[7] R. Tamura, S. Kobayashi, T. Fukuzaki, M. Isobe, Y. Ueda, J. Phys. Conf. Series 144, 012068 (2009).

[8] M. Szwaja, P. Pawlik, J.J. Wysłocki, P. Gębara, Archiv. Metall. Mater. 57, 233 (2012).

[9] J. Zhang, K.Y. Lim, Y.P. Feng, Y. Li, Scr. Mater. 56, 943 (2007).

[10] P. Pawlik, K. Pawlik, H.A. Davies, J.J. Wysłocki, W. Kaszuwara, J. Phys. Conf. Ser. 144, 012060 (2009).

[11] H. Mayot, O. Isnard, J.-L. Soubeyroux, J. Magn. Magn. Mater. 316, e477 (2008). 